\title{
Hydrocephalus: Obliterated Perimesencephalic Cisterns and the Danger of Sudden Death
}

\author{
Marjorie A. Garvey and Robert Laureno
}

\begin{abstract}
Objective: We report a possible risk factor which could identify patients with chronic hydrocephalus who are at risk for sudden death. Methods: A retrospective review of medical records and computed tomographic (CT) scans was conducted on three patients with chronic hydrocephalus who suffered acute cardiorespiratory arrest without those signs which are normally associated with a progressive worsening of hydrocephalus. Results: All three of these patients were awake and communicative shortly before the life threatening or terminal event. All had experienced some recent worsening of neurologic signs or symptoms, but none had shown a progressive impairment of consciousness or major neurologic decline ordinarily associated with life threatening elevation of intracranial pressure. Absence of the perimesencephalic cisterns on head CT scans done prior to or just after the life threatening event was the only new radiologic finding common to all these patients. Conclusions: The absence of the perimesencephalic cisterns in an awake and alert patient with severe hydrocephalus indicates that the patient may be at risk for neurogenic cardiorespiratory failure. In such cases, (especially when there has been a recent, albeit mild, change in neurologic signs or symptoms), the neurologist should urge emergency ventriculostomy or shunting for the hydrocephalus.
\end{abstract}

\begin{abstract}
RÉSUMÉ: Hydrocéphalie: oblitération des citernes périmésencéphaliques et danger de mort subite. Objectifs: Nous désirons rapporter un facteur de risque possible pouvant identifier les patients porteurs d'une hydrocéphalie chronique qui sont à risque de mort subite. Méthodes: Nous avons effectué une revue rétrospective des dossiers médicaux et des CT scans de 3 patients porteurs d'une hydrocéphalie chronique qui ont subi un arrêt cardiorespiratoire aigu sans signes normalement associés à une aggravation progressive de leur hydrocéphalie. Résultats: Les trois patients étaient éveillés et communicatifs peu de temps avant l'événement potentiellement fatal ou fatal. Tous avaient présenté une aggravation de leurs signes ou symptômes neurologiques, mais aucun n'avait présenté une détérioration de la conscience ou une détérioration neurologique majeure qu'on associe habituellement à une élévation dangereuse de la pression intracrânienne. L'absence des citernes périmésencéphaliques au CT scan fait avant ou immédiatement après l'événement potentiellement fatal a été la seule observation radiologique nouvelle chez tous ces patients. Conclusions: L'absence des citernes périmésencéphaliques chez un patient éveillé et alerte, porteur d'une hydrocéphalie sévère, indique que le patient peut être à risque de présenter une défaillance cardiorespiratoire neurogénique. Dans ces cas, spécialement quand l'état neurologique du patient s'est altéré même légèrement, le neurologue devrait recommander une ventriculostomie ou une dérivation d'urgence pour traiter l'hydrocéphalie.
\end{abstract}

Can. J. Neurol. Sci. 1998; 25: 154-158

Two important phenomena of hydrocephalus have received little attention in the medical literature. First of all, sudden death can occur in hydrocephalic patients without the warning of gradually worsening obtundation or signs of herniation. Such patients may be alert and ambulatory immediately prior to the respiratory arrest. Secondly, absence of perimesencephalic cisterns on brain imaging may indicate which patients are at risk for sudden death. Although most neurosurgeons are familiar with these aspects of hydrocephalus, leading textbooks of neurology, ${ }^{1,2}$ neurologic therapeutics, ${ }^{3,4}$ neuroradiology, ${ }^{5,6}$ neurological surgery, ${ }^{7,8}$ critical care neurology ${ }^{9}$ and emergency neurology ${ }^{10}$ do not mention let alone emphasize these facts. As a result, many neurologists, radiologists, emergency and critical care physicians may not be aware of the danger posed to these patients. Accordingly, the following cases are presented and analyzed with respect to the relevant literature.

\section{Patients and Methods}

In the two year period between January 1991 and January 1993 three patients with chronic hydrocephalus suffered sudden death or respiratory arrest. All patients were admitted to the neurology service of the Washington Hospital Center. Patients 1

\footnotetext{
From the Department of Neurology, Washington Hospital Center, and George Washington University Medical Center, Washington, DC

RECEIVED MAY 6, 1997. ACCEPTED IN FINAL FORM NOVEMBER 19, 1997.

Reprint requests to: Robert Laureno, Department of Neurology, Washington Hospital Center, 110 Irving Street, NW Washington, District of Columbia, U.S.A. 20010
} 
and 3 were seen by the authors, and Patient 2 by a colleague. The patients' medical records were retrospectively studied with particular attention to the evolution of neurologic symptoms and signs. The head CT scans performed around the time of the incident were reviewed and were compared to all available prior studies. Particular attention was paid to the degree of hydrocephalus and the state of the perimesencephalic cisterns.

\section{Case Reports}

\section{Patient 1}

This 36-year-old woman of African extraction presented with increasing headaches, nausea, vomiting, dizziness and gait imbalance.

Sarcoidosis had been diagnosed by lung biopsy four years earlier. At that time neurological examination revealed a broad-based, ataxic gait and lower extremity hyperreflexia with sustained ankle clonus. A head CT scan showed hydrocephalus (Figure 1A). Cerebrospinal fluid (obtained by lumbar puncture) was normal except for a high white cell count ( 17 white blood cells per $\mathrm{mm}^{3}$, mainly lymphocytes). Prednisone therapy for meningeal sarcoidosis brought improvement in her gait and her headaches. A year later her gait remained steady during the tapering of prednisone; the hyperreflexia persisted. At this stage she stopped attending the clinic and discontinued the prednisone without supervision.

Two years later she returned with headaches and an unsteady gait. A repeat CT scan showed increasing hydrocephalus, though the perimesencephalic cisterns were clearly visible. Once again she responded to prednisone, but she developed insulin-dependent diabetes, which persisted when the steroid therapy was stopped.

Twelve months after cessation of the prednisone her headaches returned; the head CT scan confirmed recurrent hydrocephalus. Again there was no papilledema, but there was hyperreflexia of the lower extremities as well as inability to perform tandem gait. Prednisone was carefully reinstituted, while the necessary steps were taken to maintain control of her diabetes. Because there was no response after 1 month, the daily dose was raised from $30 \mathrm{mg}$ to $40 \mathrm{mg}$. A repeat CT scan showed persistent hydrocephalus. In this scan her ventricles were enlarged, but the perimesencephalic and prepontine cisterns were clearly visible (Figure IB). Her diabetes mellitus was uncontrolled despite adjustment of her insulin dose. Thus, methotrexate was prescribed, and prednisone was decreased to $30 \mathrm{mg}$ daily.

Four days later she arrived in the emergency room at 06:00 and reported an increasingly severe headache and a 45 minute episode of diplopia, dizziness and right leg stiffness. Her blood pressure was initially $146 / 102 \mathrm{~mm} / \mathrm{Hg}$, pulse $80 /$ minute, respiratory rate $20 /$ minute and temperature 99.3 degrees $F$. Her neurological examination revealed clear mentation and normal extraocular eye movements. There was no papilledema, but there was lower extremity hyperreflexia with an ataxic gait. She ate breakfast without difficulty and received one dose of cyclobenzaprine hydrochloride (Flexeril). The serum glucose was 14.96 $\mathrm{mmol} / \mathrm{L}$, sodium was $134 \mathrm{mmol} / \mathrm{L}$, potassium $3.5 \mathrm{mmol} / \mathrm{L}$, calcium 2.45 $\mathrm{mmol} / \mathrm{L}$, blood urea nitrogen $4.99 \mathrm{mmol} / \mathrm{L}$ and creatinine $61.8 \mu \mathrm{mol} / \mathrm{L}$. At $08: 20$ her blood pressure was noted to be $148 / 94 \mathrm{~mm} / \mathrm{Hg}$ with no change in the other vital signs. At 09:45 she had a CT scan of her head which showed severe hydrocephalus with absent perimesencephalic and prepontine cisterns (Figure 2A and 2B). Neurosurgical consultation was requested. Her blood pressure was 140/80 at 10:45, 15:30 and at 18:00; other vital signs were also stable. At 18:00 she was alert and responsive. She had no new complaints; a relative visited her.

When the neurosurgeon arrived at 18:35 the patient was unresponsive, pulseless, and without respiration. Efforts at cardiopulmonary resuscitation failed. Her family did not grant permission for autopsy.

\section{Comment}

The increasing headache, the transient episode of dizziness, diplopia and leg weakness prompted her visit to the emergency room. There was absence of perimesencephalic cisterns on head CT scan. None of her prior head CT scans had shown compression of the perimesencephalic cisterns though the extent of the hydrocephalus during prior exacerbations had been similar to that seen on the preterminal scan.
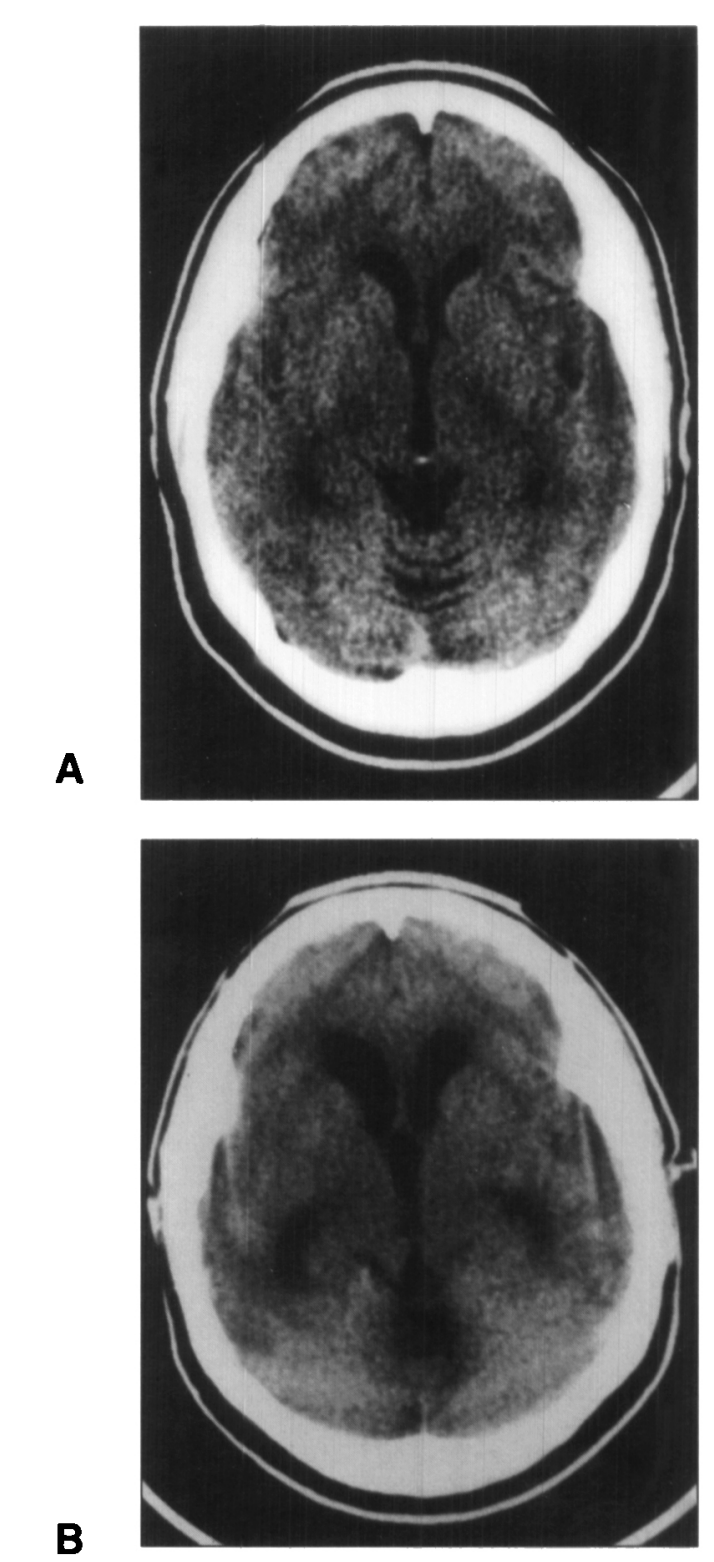

Figure 1: (Patient I) IA. CT scan after successful medical treatment of hydrocephalus, 5 years before death. $1 B$. CT scan during exacerbation of hydrocephalus, weeks before death. Both scans show patency of the perimesencephalic cisterns.

\section{Patient 2}

This 26-year-old non-English-speaking native South American man had suffered with increasingly frequent and severe headaches for 20 months. He went to the Emergency Department of another institution where a head CT scan revealed hydrocephalus. Accordingly, he was scheduled for a neurosurgical consultation, but he did not appear for this appointment.

Six months later he was seen by another physician for the same complaint. With an English-speaking family member acting as interpreter, he described his headaches as a posterior head pressure which radiated bifrontally. He reported that the tests done previously had been normal. Carbamazepine was prescribed without effect. One week later he was admitted with a particularly severe headache after one day of vomiting. At that stage he was awake and alert. There was papilledema on the right. Otherwise cranial nerve examination, including the pupils, was normal. There was generalized hyperreflexia but no Babinski sign. 
A

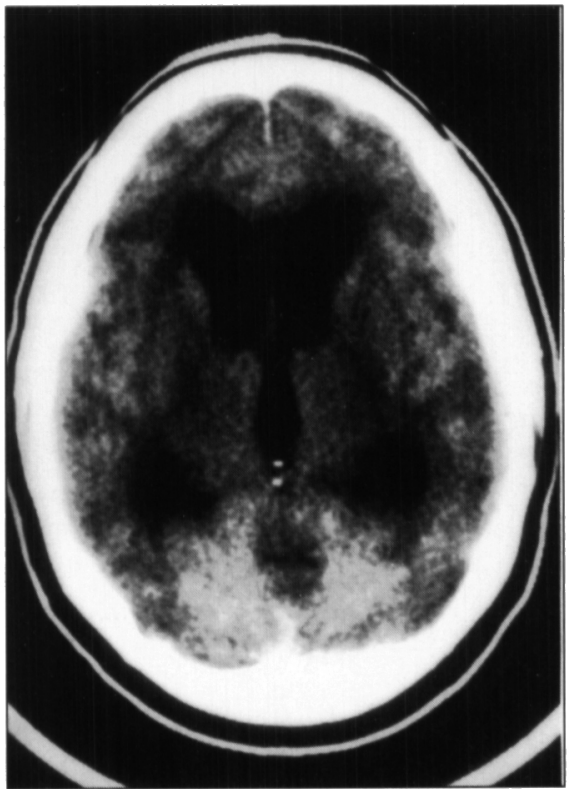

B

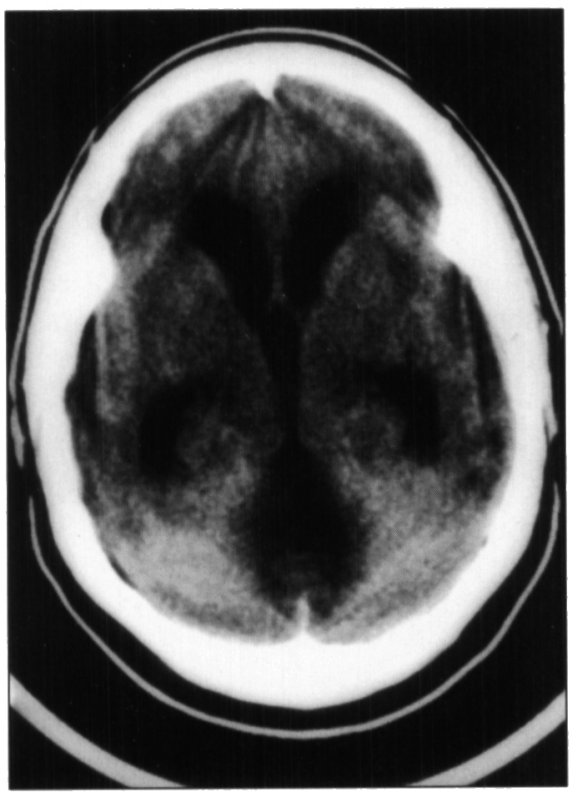

Figure 2: (Patient 1) A and B: Two images from the CT scan taken 9 hours prior to death. All subarachnoid CSF spaces are obliterated.

His blood pressure was $120 / 80 \mathrm{~mm} / \mathrm{Hg}$, temperature 98.1 degrees F., pulse 68/minute and respiratory rate 18/minute. A head CT scan done at 14:00 revealed severe dilation of the lateral, third and fourth ventricles with bilateral effacement of the cerebral sulci. There was obliteration of perimesencephalic and prepontine cisterns (Figure 3A and 3B).

The situation was perceived as urgent; emergency neurosurgical consultation was requested for treatment of the hydrocephalus. At 15:35 he continued to complain of photophobia and severe headache. He was drowsy, but he responded appropriately to commands. The neurosurgeon was uncomfortable getting consent from the patient due to the drowsiness and language barrier. As no interpreter was available he attempted to get consent from relatives by telephone. They refused to authorize ventriculostomy by telephone and arrangements were made for transfer to the intensive care unit. At 16:00 he was noted to be awake and complained to the nursing staff of his continuing headache. At that stage he was afebrile with blood pressure at $130 / 90 \mathrm{~mm} / \mathrm{Hg}$ and pulse of $60 /$ minute. At 16:50 he was found unresponsive and pulseless; there was no recordable blood pressure and no respiration. Although

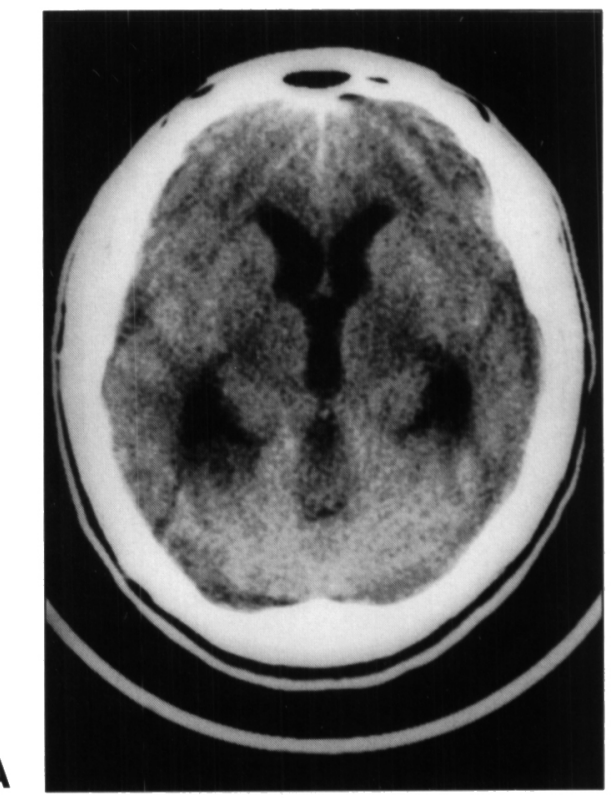

A

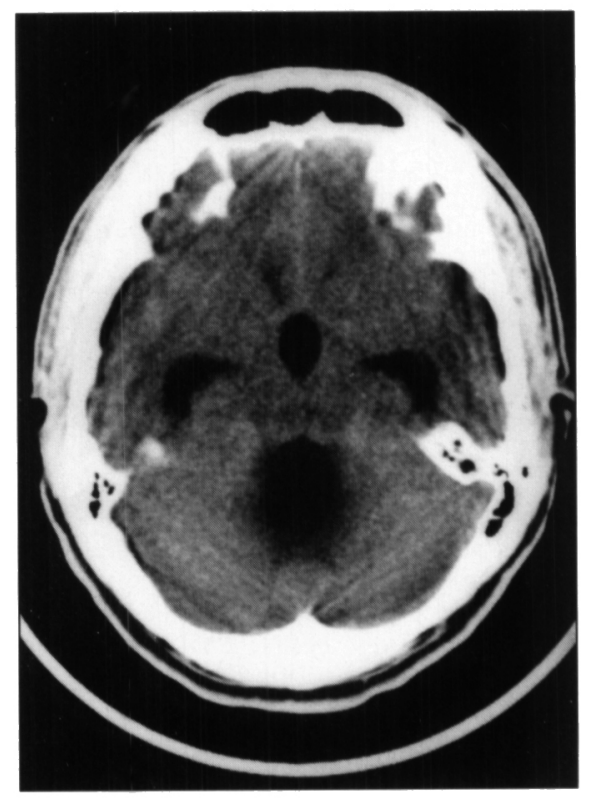

B

Figure 3: (Patient 2) A and B: Two images from the CT scan taken 3 hours prior to death. All subarachnoid CSF spaces are obliterated.

cardiopulmonary resuscitation was initiated, ventricular fibrillation could not be converted. At autopsy there was severe hydrocephalus due to a multilobulated cystic lesion (cysticercus racemosus) in the fourth ventricle. There was no cardiac or pulmonary abnormality.

\section{Comment}

Although hydrocephalus caused this man's cardiorespiratory arrest, he did not have any substantial period of stupor or coma prior to his demise. The increasing headache and, eventually, the drowsiness were the only harbingers of the catastrophic outcome. The head CT scan showed severe hydrocephalus and the perimesencephalic cisterns were obliterated.

\section{Patient 3}

This 71-year-old woman of Italian ancestry had been known to have diplopia and chronic hydrocephalus due to a left sphenoid wing meningioma. At the time of diagnosis 10 years prior to admission, the tumor already had grown into the nasopharynx where it had been biopsied. At 
that time she also had a partial left third nerve palsy, conductive hearing impairment on the left, bilateral hyperreflexia in the legs, bilateral Babinski signs, mild gait unsteadiness and the syndrome of inappropriate secretion of antidiuretic hormone (SIADH). At that point she had benefited from fluid restriction for the SIADH and myringotomy tubes to drain middle ear fluid (the tumor had occluded the opening of the Eustachian tube). She had declined neurosurgical intervention and had been comfortable with this conservative management for ten years until the recent worsening.

At the time she returned to the neurologist to be evaluated for increasing headache and imbalance, evaluation showed little progression from her prior examinations. The only new finding was an inability to perform tandem gait. Magnetic resonance imaging showed that the meningioma involved the left cavernous sinus and encased the left carotid artery. The tumor compressed the chiasm and the left optic nerve, and extended into the right cavernous sinus. It also extended down the clivus to the pontomedullary junction, where it compressed the pons and fourth ventricle. The lateral and third ventricles were dilated. The hydrocephalus, however, showed no clear change from that found on a scan done 4 years previously; the fourth ventricle was slightly effaced and the perimesencephalic cisterns were clearly visible.

Neurosurgical consultation was requested. They attributed her worsened symptoms to the hydrocephalus and recommended a sub-occipital decompression of the posterior fossa intended to alleviate the hydrocephalus. Post-operatively she developed a cerebrospinal fluid (CSF) fistula which drained through her incision. A head CT scan on the fourth post-operative day showed partial effacement of the fourth ventricle and the perimesencephalic cisterns, but the lateral ventricles were normal in size. For the persistent CSF fistula at the incision site a lumbar drain was inserted on the fifth post-operative day, which, with resolution of the CSF leak, was removed on the eighth post-operative day.

On the following day CSF had once again started to leak from the incision site, and she complained of a moderate new headache. At 16:30 she was very apathetic and drowsy but she was able to follow commands and let her nurse know of her headache. She had no difficulty moving her upper or lower extremities and she had equal, reactive pupils. At 17:15 she was noted to have agonal respiration, with a strong pulse of 100/minute and blood pressure of 140/70. Respiratory support was instituted, initially with bag and mask and subsequently with endotracheal intubation. Shortly thereafter, however, she had a cardiac arrest. After successful cardiopulmonary resuscitation a CT head scan showed severe hydrocephalus with enlarged lateral and third ventricles. The fourth ventricle, perimesencephalic and pre-pontine cisterns were not visible. Following emergency ventriculostomy she opened her eyes spontaneously and responded appropriately to commands. A repeat head scan showed decompressed lateral ventricles, partial opening of the perimesencephalic cisterns and persisting effacement of the fourth ventricle. After repeated unsuccessful attempts to discontinue the external CSF drainage, a ventriculoperitoneal shunt was placed. She was transferred to an inpatient rehabilitation facility from which she returned home. Two years later she continues to walk without a cane.

\section{Comment}

Rapidly worsening hydrocephalus resulted in agonal respiration without any premonitory stupor or coma. Almost certainly, all the cisterns of the posterior fossa were compressed prior to the arrest, although CT scan documentation came only immediately after the arrest. The mild cognitive changes and the drowsiness were the only harbingers of the respiratory arrest.

\section{Discussion}

Each of these 3 inpatients experienced respiratory or cardiorespiratory arrest due to hydrocephalus. Each patient had been awake and communicative less than one hour before being found unresponsive. Nevertheless, each had changed clinically in the days or hours before the respiratory arrest. The new symptoms or signs were drowsiness, apathy, increasing headache and an episode of diplopia and leg weakness. In addi- tion, each patient had absent perimesencephalic cisterns on head CT scan (documented prior to respiratory arrest in 2 cases and immediately after it in 1 case). These cases remind us that hydrocephalus can cause sudden death, and they support the idea that patients with absent perimesencephalic cisterns are at risk for this catastrophic event.

In 1970, Milhorat reported that acute hydrocephalus could result in an acute life threatening event." Other reports give the clinical details of patients with both acute ${ }^{12,13}$ and chronic hydrocephalus who had acute life threatening events or suffered sudden death. ${ }^{14-17}$ Most of the patients reported had non-specific complaints such as an increase in headaches or lethargy. While the majority showed stupor and clinical signs of raised intracranial pressure (abducens nerve palsy or anisocoria) early in the course of their deterioration, a small number of patients had few if any clinical symptoms or signs prior to their sudden death or lifethreatening event. For example, the patient reported by Yanofsky et al. ${ }^{13}$ had no neurological signs of raised intracranial pressure prior to a cardiorespiratory arrest in the middle of a conversation.

Only a single article about pediatric patients has suggested that a feature on CT scan may warn of the risk for sudden death. ${ }^{17}$ In this article, each of the 7 children with ventriculoperitoneal shunt failure had absent perimesencephalic cisterns on head CT scans done hours prior to their acute collapse. Each had had a brief period of non-specific complaints such as headache and lethargy that warned of the shunt failure. Four of the patients then had a rapid deterioration in neurological function and underwent emergency surgery to revise the ventriculoperitoneal shunts. Three patients, however, suffered sudden cardiac arrest without warning, and two of these died. In all of the survivors the perimesencephalic cisterns re-appeared once the shunt was revised. Johnson et al. ${ }^{17}$ also reviewed 137 head CT scans of an additional 43 children with shunted hydrocephalus who were under their care. Only four patients showed absence of the perimesencephalic cisterns on one of their CT scans. All subsequently had shunt revisions with reappearance of the perimesencephalic cisterns on the following CT scan. Thus of the 50 patients whose CT scans were reviewed by these authors, 39 children had patent perimesencephalic cisterns; none of them experienced cardiac or respiratory arrest. Of the 11 patients with absent perimesencephalic cisterns, 7 suffered life threatening events and 2 of these died. The authors concluded that absence of the perimesencephalic cisterns was a sign of life threatening shunt failure.

Absence of perimesencephalic and basal cisterns on CT indicates a critical situation in disorders other than hydrocephalus. This sign has been recognized as an indicator of poor outcome in head injured patients. ${ }^{18.19}$ Tasker and colleagues ${ }^{20}$ have shown that in children with nontraumatic coma and cerebral edema, absence of the chiasmatic, and perimesencephalic cisterns is frequently associated with intracranial pressures of $20-40 \mathrm{mmHg}$. When all the perimesencephalic cisterns are obliterated, the intracranial pressure is usually over $40 \mathrm{mmHg}$. In addition, obliteration of the perimesencephalic cisterns on CT scan has been reported as a feature of so-called "central" transtentorial herniation. ${ }^{21}$ Finally, absence of perimesencephalic cisterns has been related to brainstem dysfunction and increased intracranial pressure after acute stroke. ${ }^{22}$

Experimental literature confirms that compromise of the 
perimesencephalic cisterns due to an expanding supratentorial mass can be related to apnea in dogs. Magnetic resonance (MR) imaging performed simultaneously with left hemisphere epidural balloon inflation shows that cardio-respiratory dysfunction is first clinically apparent when the pre-pontine and perimesencephalic cisterns become partially occluded; increased compression of the posterior fossa contents, including obliteration of the cisterna magna, coincides with apnea. ${ }^{23}$

Previously, only the report on hydrocephalic children by Johnson et al. ${ }^{17}$ specifically linked an absence of the perimesencephalic cisterns with the risk of sudden death. The present report of three patients suggests that absence of perimesencephalic cisterns is an ominous finding in adult hydrocephalus (both acute and chronic) as it is in pediatric hydrocephalus with shunt failure. Together these cases demonstrate that some patients with absent perimesencephalic cisterns die suddenly without the warning of progressive obtundation or brainstem dysfunction. Thus, hydrocephalic patients with even mild or episodic worsening of neurologic symptoms should have immediate CT head scanning; urgent evaluation for emergency surgical intervention is essential if obliteration of the perimesencephalic cisterns is present.

\section{ACKNOWLEDGEMENTS:}

We thank Dr. Adrienne Smith for providing information on her patient.

\section{REFERENCES}

1. Bradley WG, Daroff RB, Fenichel GM, Marsden CD, eds. Neurology in Clinical Practice. 2nd ed. Boston: Butterworth Heinemann, 1996.

2. Walton J, ed. Brain's Diseases of the Nervous System. 10th ed. Oxford: Oxford University Press, 1993.

3. Johnson RT, ed. Current Therapy in Neurologic Disease. Philadelphia: BC Decker, 1993.

4. Samuels M, ed. Manual of Neurology: Diagnosis and Therapy. 5th ed. Boston: Little, Brown Company, 1996.

5. Atlas SW, ed. Magnetic Resonance Imaging of the Brain and Spine. 2nd ed. Philadelphia: Lippincott-Raven, 1996.

6. Osborne A, ed. Diagnostic Radiology. St Louis: Mosby, 1994.
7. Youmans JK, ed. Neurological Surgery. 3rd ed. Philadelphia: WB Saunders \& Company, 1990.

8. Wilkins RH, Rengachary SS, eds. Neurosurgery. 2nd ed. New York: McGraw Hill, 1996.

9. Ropper AH, ed. Neurological and Neurosurgical Intensive Care. New York: Raven Press, 1993.

10. Salcman M, ed. Neurological Emergencies. 2nd ed. New York: Raven Press, 1990.

11. Milhorat TH. Acute hydrocephalus. New Engl J Med 1970; 283: 857-859.

12. Cotton MF, Reiley T, Robinson CC, et al. Acute aqueductal stenosis in a patient with Epstein-Barr virus infectious mononucleosis. Pediatr Inf Dis J 1994; 13: 224-227.

13. Yanofsky CS, Hanson PA, Lepow M. Parainfectious acute obstructed hydrocephalus. Ann Neurol 1981; 10: 62-63.

14. McHugh PR. Occult hydrocephalus. Quart J Med 1964; 33: 297. 308.

15. Hayden PW, Shurtleff DB, Stuntz TJ. A longitudinal study of shunt function in 360 patients with hydrocephalus. Dev Med Child Neurol 1983; 25: 334-337.

16. Staal MJ, Meihuizen-de Regt MJ, Hess J. Sudden death in hydrocephalic spina bifida aperta patients. Pediatr Neurosci 1987; 13: 13-18.

17. Johnson DL, Fitz C, McCullough DC, Schwarz S. Perimesencephalic cistern obliteration: a CT sign of life-threatening shunt failure. J Neurosurg 1986; 64: 386-389.

18. van Dongen KJ, Braakman R, Gelpke GJ. The prognostic value of computerized tomography in comatose head-injured patients. J Neurosurg 1983; 59: 951-957.

19. Toutant SM, Klauber MR, Marshall LF, et al. Absent or compressed basal cisterns on first CT scan: ominous predictors of outcome in severe head injury. J Neurosurg 1984; 61: 691-694.

20. Tasker RC, Matthew DJ, Kendall B. Computed tomography in the assessment of raised intracranial pressure in non-traumatic coma. Neuropediatrics 1990; 21: 91-94.

21. Nguyen JP, Djindjian M, Brugieres P, et al. Anatomy - computerized tomography correlations in transtentorial brain herniation. J Neuroradiol 1989; 16: 181-196.

22. Klug N, Hoffman O, Buss K, Laun A, Agnoli AL. Decerebrate rigidity and vegetative signs in the acute midbrain syndrome with special regard to motor activity and intracranial pressure. Acta Neurochir 1984; 72: 219-233.

23. Thuömas KA, Vlajkovic JC, Ganz JC, et al. Progressive brain compression. Changes in vital physiological variables, correlated with brain tissue water content and brain tissue displacement. Experimental MR imaging in dogs. Acta Radiol 1993; 34: 289295. 